\title{
Formulation and Evaluation of Sustained Release Ibuprofen Matrix Tablets Using Starch from Maize Genotypes as Polymer
}

\author{
Lateef Gbenga Bakre1*, Emmanuel Akinyele1, Oluyemisi Bamiro¹, Olutayo Adeleye1, Olobayo Kunle² \\ 1. Department of Pharmaceutics and Pharmaceutical Technology, Faculty of Pharmacy, Olabisi Onabanjo University, Nigeria \\ 2. Department of Pharmaceutical Technology and Raw Materials Development, National Institute for Pharmaceutical Research and Development, Nigeria
}

\begin{abstract}
Objective: Maize plants have been genetically engineered to produce genotypes with agriculturally desirable traits such as high starch content, pest resistance and increased nutritional value. Maize starch has been widely used as an excipient in pharmaceutical formulations. This study aims to produce sustained release ibuprofen tablets using starch obtained from different maize genotypes as polymers. Methods: Ibuprofen matrix tablets were prepared with the starches isolated from the maize genotypes and the unmodified plant. The mechanical properties of the tablets were evaluated using the crushing strength (CS), friability (FR) and CSFR. A 32 factorial design was applied using the time taken for $50 \%$ (T50) and $90 \%$ (T90) drug release as dependent variables while the polymer-drug ratio and polymer types were the independent variables. Results: The CSFR was significantly higher $(p<0.05)$ in tablets formulated with the starches obtained from the modified cultivars. Drug release for all the formulations fitted the Higuchi model while the mechanism of release was generally by super case transport. The polymer-drug ratio and polymer type strongly interacted to increase the dissolution times (T50 and T90) and CSFR. Starches isolated from the genetically modified cultivars provided a more sustained release of ibuprofen from the tablet matrix through erosion and polymer relaxation. Conclusion: The results indicate that the genetic modification of maize can quantitatively affect the drug release modifying effects of maize starch in drug formulation.
\end{abstract}

Keywords: maize genotypes, starch, ibuprofen matrix tablets, sustained release

Received 10 February 2021 / Accepted 29 May 2021

\section{Introduction}

Maize (Zea mays) is a major staple grown all over the world particularly Asia, Latin America and Africa. It is the third most important cereal worldwide after wheat and rice and is commonly referred to as the "cereal of the future" due to its high nutritional value and the diverse use of its byproducts $[1,2]$. It has been estimated that the demand for maize will increase by $50 \%$ from 558 million metric tons in 1995 to 837 million metric tons in 2020 [3]. Agricultural research has focused on a large number of breeding programs for maize to develop new genotypes or cultivars with improved qualities. These qualities include better yield, increased starch content, enhanced tolerance to drought, pest, heat stress, cold temperature stress, water stress, weed competition, and herbicides. These breeding programs have yielded remarkable success with nearly a six-fold increase in grain yields and about $60 \%$ improvement in the genetic component of the grains [4]. One of such programs by the International Institute of Tropical Agriculture (IITA) in Nigeria has led to the production of Pro vitamin A-rich maize genotype (PVA 39) and drought resistance genotype (IWD 15).

Starch is a major constituent of maize and is isolated from the endosperm of the kernel by the wet milling process. Its functional versatility is mainly due to its physicochemical properties, biodegradability, relative ease of

* Correspondence to: Lateef Gbenga Bakre

E-mail: lateefbakr@yahoo.com modification and biocompatibility. Maize starch has been widely employed as diluent, disintegrant and binder in tablet dosage forms. Modification of native starches have been carried out to obtain newer excipients with improved functionality [5-8]. Starch functionality depends on the starch structure and composition, which vary with genotypes [9]. Our earlier studies have shown that the genetically modified starches PVA 39 and IWD 15 have higher amylose content, swelling capacity, viscosity and enthalpies of gelatinization than native maize starch. The increased amylose content due to modification was found to positively affect important pharmaceutically properties like moisture sorption and viscosity [10]. These genotypic modifications of maize might thus affect the functionality of its starch in pharmaceutical dosage forms in which it is used as an excipient. This study aims to determine the effect of genotypic modification on the performance of starches isolated from maize genotypes PVA 39 (SA) and IWD 15 (SB) as sustained release polymers in ibuprofen tablets. This will be compared with the properties of tablets containing starch obtained from unmodified maize (SC). Ibuprofen, a widely used over -the- counter nonsteroidal anti-inflammatory agent is used to treat chronic pain, inflammation and fever. It is a non-selective cyclo-oxygenase- 1 and cyclooxygenase- 2 inhibitor with an elimination half- life of $2 \mathrm{hrs}$ hence it has to be administered usually as a $400 \mathrm{mg}$ tablet three times a day. This makes it a suitable drug candidate for sustained release formulation as in this study [11]. 


\section{Materials and methods Materials}

Ibuprofen powder and lactose monohydrate (CAS 6404451-5) were purchased from Sigma Aldrich GmbH (Steinheim, Germany) while magnesium stearate was obtained from BDH Chemicals, UK. Maize grain genotypes (PVA 39 and IWD 15) were obtained from the International Institute of Tropical Agriculture (IITA), Nigeria. Starch extraction was done using established methods [12]. All other reagents used were of analytical grade.

\section{Preparation of lbuprofen matrix tablets}

The tablets $(500 \mathrm{mg}$ ) were made by compressing powder blends according to the formula in Table 1 on a Carver hydraulic press using the direct compression method. A compression pressure of 1.0 metric ton and dwell time of 30 seconds was used. Prior to each compression cycle, the punches and die assembly were lubricated with a $2 \%$ magnesium stearate solution in $96 \%$ alcohol. The compressed tablets were kept in sealed envelopes prior to further analysis

\section{Experimental Design}

A $3^{2}$ factorial design was carried out by making use of two factors at three levels. Table III shows the nine possible combinations. The dependent variables were CSFR, the time taken for $50 \%\left(\mathrm{~T}_{50}\right)$ and $90 \%\left(\mathrm{~T}_{90}\right)$ drug release while the polymer-drug ratio and polymer types were taken as independent variables.

\section{Physical properties of Ibuprofen tablets}

Tablet thickness was determined with a micrometer screw gauge (Type TB-24; Erweka, Heusenstamm, Germany) while friability was measured using a Roche (Erweka Gmbh, Heusenstamm, Germany) friabilator operated for $4 \mathrm{~min}$ at a speed of $25 \mathrm{rpm}$. The tablet hardness was measured with a Monsanto hardness tester (Copley Scientific Limited, Nottingham, UK). The weight of twenty randomly selected tablets was taken separately to check for variation from the average weight.

\section{In vitro release studies}

Dissolution studies were carried out in a dissolution apparatus (Model NE4-COPD; Copley Scientific Limited,
Nottingham, UK) with phosphate buffer solution $\mathrm{pH} 7.4$ maintained at $37 \pm 0.5^{\circ} \mathrm{C}$ as the medium. A tablet from each batch was placed in $900 \mathrm{ml}$ of the medium and the apparatus operated at $100 \mathrm{rpm}$. A $10 \mathrm{~mL}$ sample was withdrawn at $5,10,15,30,60,120,180,300,420,540$ and 720 minutes intervals respectively and replaced with equal volumes of fresh dissolution medium maintained at the same temperature. The withdrawn samples were filtered, diluted 10 -fold and the absorbance measured at a wavelength of $221 \mathrm{~nm}$ on a UV spectrophotometer (T85 PG Instruments Limited, UK). The tests were carried out in triplicates.

\section{Kinetics of Drug Release}

The in vitro release data were fitted into various kinetics models [13-17]

$$
\begin{aligned}
& \text { Higuichi model: } \mathrm{Q}=\mathrm{k}_{\mathrm{H}} \mathrm{t}^{1 / 2} \\
& \text { Hixson: }(100-\mathrm{Q})^{1 / 3}=100^{1 / 3}-\mathrm{k}_{\mathrm{S}} \mathrm{t} \\
& \text { Zero-order: } \mathrm{Q}=\mathrm{K}_{0} \mathrm{t} \\
& \text { First order: } \log \mathrm{Q}=\log \mathrm{Q}_{0}-\mathrm{K}_{1} \mathrm{t} / 2.303 \\
& \text { Korsmeyer-Peppas: } \quad \mathrm{Q} / \mathrm{Q}_{0}=\mathrm{kt}^{\mathrm{n}}
\end{aligned}
$$

The mechanism of drug release was obtained by plotting log cumulative percentage of the drug release (first $60 \%$ drug release) versus log time. The parameter $Q$ is the amount of drug released after time $t, Q_{0}$ is the initial concentration of drug, $\mathrm{Q} / \mathrm{Q}_{0}$ is the fraction of drug released, $\mathrm{k}_{\mathrm{H}}, \mathrm{k}_{1}, \mathrm{k}_{0}, \mathrm{k}_{\mathrm{s}}$ and $\mathrm{k}$, represent the release constants for Higuchi, first-order, zero-order, Hixson and Korsmeyer-Peppas models respectively. The parameter, n Korsmeyer-Peppas equation represents the drug release mechanism. For a cylindrical tablet, values of $\mathrm{n}$ equals to 0.5 indicates a Fickian diffusion mechanism, $0.50<\mathrm{n}<1$ represents non-Fickian transport, $\mathrm{n}=1$ is Case II transport or typical zero- order, and $n>1$ indicates super case II transport [18].

\section{Data analysis}

The data was subjected to a two- way analysis of variance (ANOVA). $\mathrm{P} \leq 0.05$ were considered significant at $95 \%$

\begin{tabular}{|c|c|c|c|c|c|c|c|c|c|c|}
\hline Ingredients (\%w/w) & Pharmaceutical role & F1 & $\mathbf{F} 2$ & F3 & F4 & F5 & F6 & F7 & F8 & F9 \\
\hline Ibuprofen & API & 20 & 20 & 20 & 20 & 20 & 20 & 20 & 20 & 20 \\
\hline SA & Polymer & 20 & 40 & 60 & -- & -- & -- & -- & -- & -- \\
\hline SC & Polymer & -- & -- & -- & -- & -- & -- & 20 & 40 & 60 \\
\hline Talc & Glidant & 1 & 1 & 1 & 1 & 1 & 1 & 1 & 1 & 1 \\
\hline Lactose & Diluent & 58 & 38 & 18 & 58 & 38 & 18 & 58 & 38 & 18 \\
\hline Polymer: drug ratio & & $1: 1$ & $2: 1$ & $3: 1$ & $1: 1$ & $2: 1$ & $3: 1$ & $1: 1$ & $2: 1$ & $3: 1$ \\
\hline
\end{tabular}
confidence interval. Contour and surface plots were generated using Minitab 19 Statistical Software (Minitab Inc., USA).

Table 1. Formula for Ibuprofen Matrix Tablet $(\approx 500 \mathrm{mg}$ ) 


\section{Results and Discussion}

\section{Mechanical properties of Ibuprofen tablets}

The determination of the mechanical strength of a tablet is an essential aspect of quality assurance in tablet production. The crushing strength and friability are two important parameters used to evaluate the mechanical properties of tablet formulations [19].

Table II reveals that all the starch samples produced soft tablets with crushing strength ranging between 0.83-1.97 $\mathrm{kgF} / \mathrm{cm}^{3}$ decreasing as the polymer: drug ratio increases. None of the formulations met the limit for friability with values above $1 \%$. The weight variation was observed to be high. This is because ibuprofen is known to exhibit poor tableting behavior because of its hydrophobic structure, low flowability, and tendency to stick to the tablet punches, all of which have been shown to lead to variations in tablet weight [11]. The crushing strength/friability ratio (CSFR) has been shown to be a useful parameter for tablet quality because it simultaneously evaluates both the strength and weakness of tablets [20]. Tablets with higher CSFR are stronger than those with low values [21]. The CSFR was significantly higher $(\mathrm{p}<0.05)$ in tablets formu- lated with the starches obtained from the maize genotypes as shown in Table II. Formulation F3, containing 60\% of SA was the strongest with CSFR value of 0.92. This can be correlated with its having the highest amylose content of the three starches [10]. Reports have shown that there is a direct relationship between the amylose content, paste viscosity, bondt strength and tablet mechanical strength [22]. (Table III and IV)

\section{In vitro release properties.}

A good tablet should combine good physical strength with adequate release profile. Drug dissolution precedes absorption and is related to bioavailability. Table III shows that the higher the polymer: drug ratio, the slower the drug release from the tablet. The decrease in the rate of drug release could be due to the increased polymer concentration rendering the gel matrix less porous and consequently slowing drug diffusion out of it [23]. Although Ibuprofen tablets containing starch from the maize genotypes provided a more sustained release of the drug, the difference was not significant $(\mathrm{p}<0.05)$.

Table II. Mechanical properties of Ibuprofen Tablet Formulations

\begin{tabular}{|c|c|c|c|c|}
\hline Formulation code & Crushing strength(KgF/cm³) & Friability (\%) & CSFR & Weight Uniformity (mg) \\
\hline $\mathrm{F} 1$ & $1.97 \pm 0.06$ & 3.06 & 0.64 & $0.46 \pm 0.02$ \\
\hline F2 & $1.83 \pm 0.21$ & 6.46 & 0.28 & $0.44 \pm 0.01$ \\
\hline F3 & $1.07 \pm 0.12$ & 1.16 & 0.92 & $0.46 \pm 0.01$ \\
\hline F4 & $1.77 \pm 0.25$ & 2.10 & 0.84 & $0.44 \pm 0.01$ \\
\hline F5 & $1.03 \pm 0.06$ & 3.07 & 0.34 & $0.45 \pm 0.01$ \\
\hline F6 & $0.90 \pm 0.10$ & 4.38 & 0.21 & $0.45 \pm 0.01$ \\
\hline F7 & $0.83 \pm 0.15$ & 4.05 & 0.20 & $0.44 \pm 0.01$ \\
\hline F9 & $0.87 \pm 0.15$ & 4.19 & 0.21 & $0.46 \pm 0.00$ \\
\hline
\end{tabular}

Table III. $3^{2}$ Factorial design for Ibuprofen tablet formulations

\begin{tabular}{|c|c|c|c|c|c|c|c|}
\hline \multirow[t]{2}{*}{ Batch } & \multicolumn{2}{|c|}{ Variable levels } & \multicolumn{2}{|c|}{ Real values } & \multicolumn{3}{|c|}{ Response } \\
\hline & $\mathbf{X} 1$ & $\mathrm{X} 2$ & X1 (Polymer type) & X2 (Polymer: drug) & CSFR & $\mathrm{T}_{50}(\mathrm{hrs})$ & $\mathrm{T}_{90}$ (hrs) \\
\hline $\mathrm{F} 1$ & -1 & -1 & SA & $1: 1$ & 0.64 & 2.31 & 4.19 \\
\hline $\mathrm{F} 2$ & -1 & 0 & SA & $2: 1$ & 0.28 & 3.00 & 5.27 \\
\hline F3 & -1 & +1 & SA & $3: 1$ & 0.92 & 4.04 & 6.74 \\
\hline F4 & 0 & -1 & SB & $1: 1$ & 0.84 & 2.96 & 5.26 \\
\hline F5 & 0 & 0 & SB & $2: 1$ & 0.34 & 3.26 & 5.63 \\
\hline F6 & 0 & 1 & SB & $3: 1$ & 0.21 & 4.71 & 7.76 \\
\hline F8 & +1 & 0 & SC & $2: 1$ & 0.25 & 2.70 & 4.71 \\
\hline F9 & +1 & +1 & SC & $3: 1$ & 0.21 & 3.13 & 5.30 \\
\hline
\end{tabular}

Table IV. Release kinetics parameters for Ibuprofen tablet formulations

\begin{tabular}{|c|c|c|c|c|c|}
\hline \multirow{3}{*}{ Formulations } & \multirow{3}{*}{$\begin{array}{c}\text { Power law } \\
\text { n }\end{array}$} & \multicolumn{4}{|c|}{ Drug release models } \\
\hline & & \multicolumn{4}{|c|}{$\mathbf{R}^{2}$} \\
\hline & & Zero-order & First order & Higuchi & Hixson \\
\hline F1 & 1.16 & 0.8402 & 0.9191 & 0.9844 & 0.8952 \\
\hline F2 & 0.95 & 0.8501 & 0.9101 & 0.9876 & 0.8914 \\
\hline F3 & 0.28 & 0.9445 & 0.9678 & 0.9881 & 0.9611 \\
\hline F4 & 2.43 & 0.8264 & 0.8926 & 0.9787 & 0.8718 \\
\hline F5 & 0.94 & 0.8690 & 0.9200 & 0.9910 & 0.9040 \\
\hline F6 & 3.40 & 0.9580 & 0.9759 & 0.9855 & 0.9703 \\
\hline F7 & 1.22 & 0.8470 & 0.9195 & 0.9870 & 0.8974 \\
\hline F8 & 2.71 & 0.8860 & 0.9426 & 0.9919 & 0.9256 \\
\hline F9 & 3.97 & 0.9240 & 0.9620 & 0.9940 & 0.9508 \\
\hline
\end{tabular}


Figure 1 shows the drug release profiles, while Table IV presents the result of the simulation of drug kinetics using the different release models. The genotypic modification of the starches did not affect the drug release model with all the formulations fitting the Higuchi model which represent the best model. The diffusion exponent, $\mathrm{n}$, in the Korsmeyer-Peppas model was greater than 1, (except for Formulations F2, F3 and F5), which indicates super case

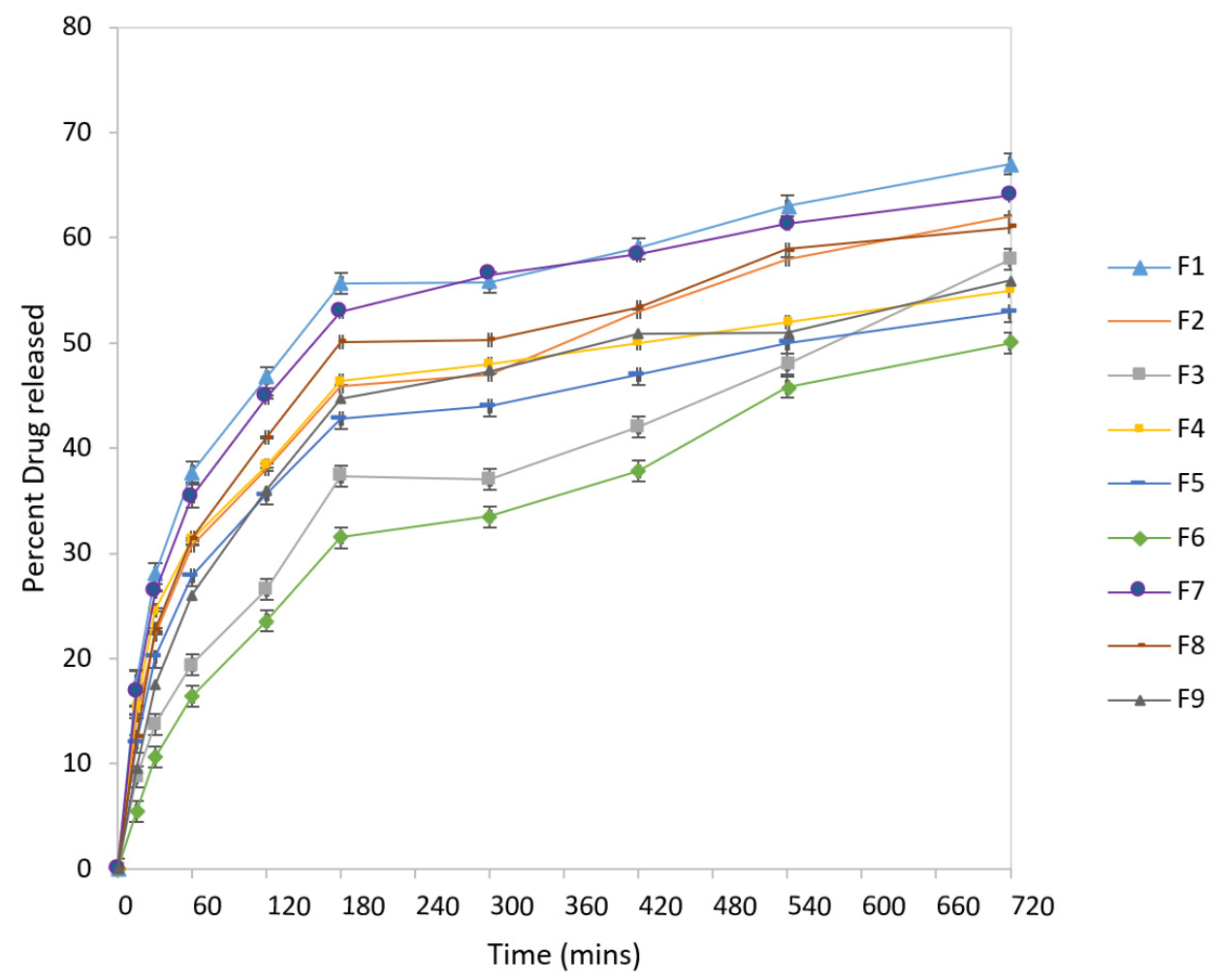

Fig. 1. Drug release profiles from Ibuprofen matrix tablets

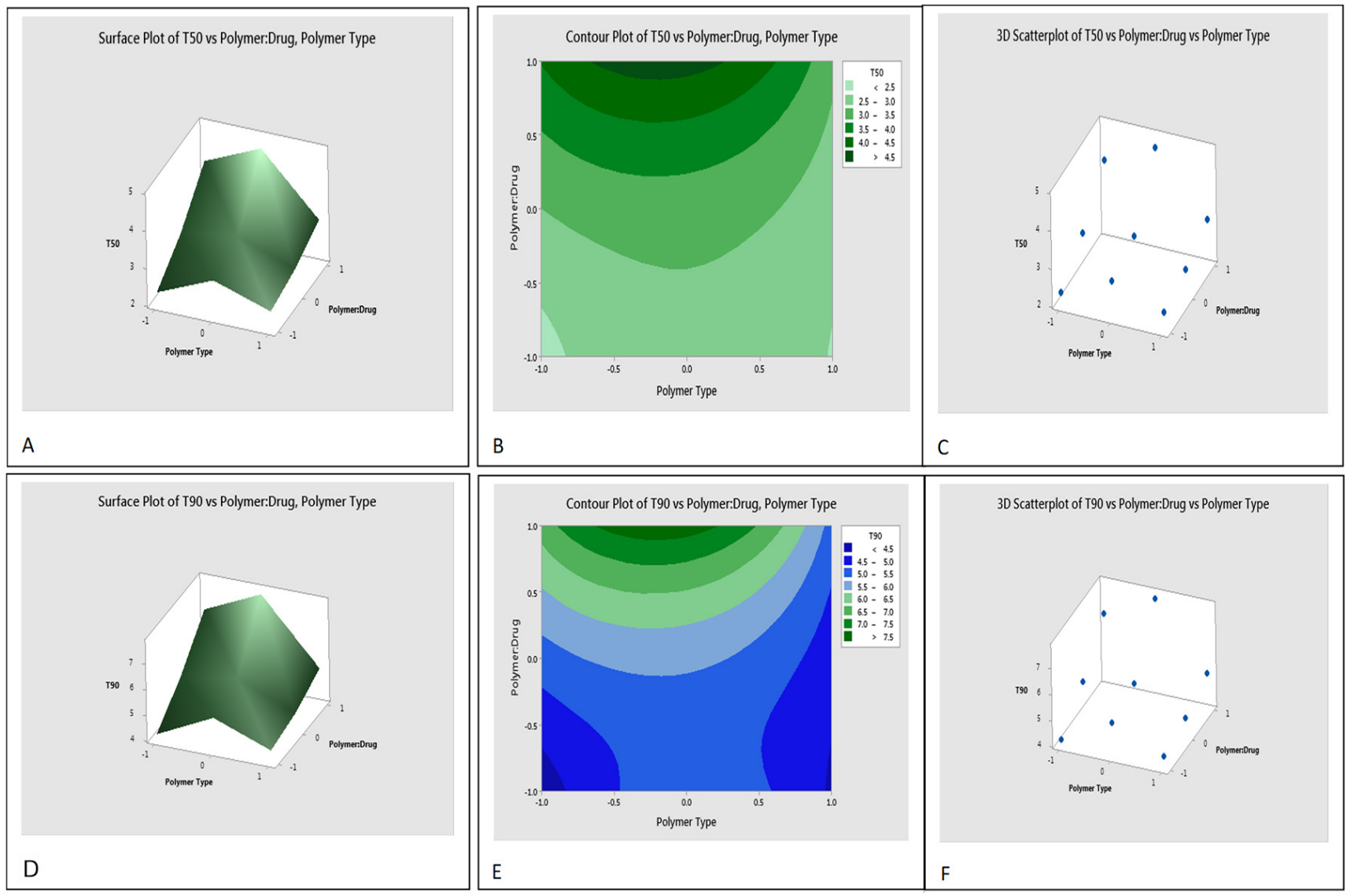

Fig. 2. Surface, Contour and 3D Scatter plots showing effect of Polymer: Drug ratio and Polymer type on Dissolution times 
transport mechanism where drug release is 8controlled by erosion and drug relaxation. Formulations F2 and F5 which contain starches from the genotypic cultivars, exhibited non-fickian diffusion. The results show that the higher the polymer: drug ratio, the higher the regression coefficient $\left(\mathrm{R}^{2}\right)$ in the zero order model. This suggests that higher polymer concentration is required for time dependent drug release which correlates with reports from previous studies [24]. Figure 2 shows the surface and contour plots which give a two dimensional view of the relationship between a response variable and two independent variables. Generally, areas with darker colour indicate stronger response. The plots reveal that polymer-drug ratio and polymer type strongly interacted to increase the dissolution times $\left(\mathrm{T}_{50}\right.$ and $\left.\mathrm{T}_{90}\right)$ and CSFR. This indicates that the modification of the starches would affect drug release from the tablets.

\section{Conclusions}

Starches obtained from genetically modified maize produced tablets of better mechanical properties than the unmodified starch. They provided a more sustained release of ibuprofen from the tablet matrix through erosion and polymer relaxation. While the qualitative formulation properties of the starches were unaffected by the genotypic modification, their quantitative effects on the drug formulation were modified. This highlights the need to carefully carry out preformulation studies before substituting starches in drug formulations.

\section{Acknowledgement}

The authors acknowledge the International Institute of Tropical Agriculture (IITA), Ibadan, Nigeria for the maize grain cultivars.

\section{Authors' contributions}

LGB (Conceptualization; Data curation; Writing - original draft, Supervision)

EA (Data curation; Methodology; Project administration) OB (Formal analysis; Validation; Writing - review \& editing)

OA (Formal analysis; Writing - review \& editing, Validation)

OK (Conceptualization; Project administration; Validation)

\section{Conflict of interest}

None to declare

\section{References}

1. Manu N, Opit GP, Osekre EA, Arthur FH, Mbata G, Armstrong P, Danso JK, McNeill SG, Campbell JF. Moisture content, insect pest infestation and mycotoxin levels of maize in markets in the northern region of Ghana. J Stored Prod Res 2019; 80:10-20
2. Suleiman R, Rosentrater KA, Bern CJ. Evaluation of maize weevils Sitophilus zeamais Motschulsky infestation on seven varieties of maize. J Stored Prod Res. 2015; 64:97-102

3. Martinez EM, Chapa-Oliver AM, Mejía-Teniente L, Torres-Pacheco I, Guevara González RG, Vazquez-Cruz MA, Cervantes-Landaverde JJ, Preciado-Ortiz RE. Genetic resistance to drought in maize and its relationship in aflatoxins production. Aflatoxins - Biochemistry and Molecular Biology. Guevara-Gonzalez RG, 2011; ed.

4. Lee EA, Tollenaar M. Physiological Basis of Successful Breeding Strategies for Maize Grain Yield. Crop Sci. 2007; 47(3):202-215.

5. Bakre LG, Osibajo DJ, Koiki AG, Bamiro OA. Material, compressional and tableting properties of Ipomea batatas (sweet potato) starch coprocessed with silicon dioxide. Acta Pharm Scientia 2019; 57 (4): 21-37.

6. Okunlola A, Ghomorai T. Development of ibuprofen microspheres using acetylated plantain starches as polymer for sustained release. J Pharm Invest 2018; 48: 551-564.

7. Builders PF, Anwunobi PA, Mbah CC, Adikwu MU. New Direct Compression Excipient from Tiger nut Starch: Physicochemical and Functional Properties. AAPS PharmSciTech 2013; 14 (2): 818-827

8. Odeniyi MA, Ayorinde JO. Effects of Modification and Incorporation Techniques on Disintegrant Properties of Wheat (Triticum Aestivum) Starch in Metronidazole Tablet Formulations. Polim Med. 2014; 44 (3): 147-15

9. Singh N, Kaur A, Shevkani K. Maize: Grain Structure, Composition, Milling and Starch Characteristics. In: Chaudhary D., Kumar S., Langyan S. (eds) Maize: Nutrition Dynamics and Novel Uses. Springer, New Delhi 2014; 65-76

10. Bakre LG, Adegbesan AD, Bamiro OA, Olayemi B, Kunle OO. Genetic modification of maize plant on the pharmaceutically important properties of its starch. Malaysian J Pharm Sci 2021 Manuscript Accepted for publication

11. Swain RP, Kumari TR, Panda S. Formulation development and evaluation of sustained release ibuprofen tablets with acrylic polymers (eudragit) and HPMC. Int J Pharm Pharmaceut Sci. 2016; 8(2) 131-135.

12. Itiola OA, Odeku OA. Packing and cohesive properties of some locally extracted starches. Trop J Pharm Res 2005; 4:363-368

13. Higuchi T. Mechanism of sustained action medication. Theoretical analysis of rate of release of solid drugs dispersed in solid matrices. J. Pharm. Sci. 1963; 52: 1145-1149.

14. Ritger R, Peppas NA. A simple equation for disposition of solute release - II. J Control Rel. 1987; 5: 37-42.

15. $\mathrm{Xu} \mathrm{G}$, Sunada $\mathrm{H}$. Influence of formation changes on drug release kinetics. Chem Pharm Bull. 1995; 43: 483-487.

16. Siepmann J, Peppas NA. Modeling of drug release from delivery systems based on hydroxypropyl methylcellulose (HPMC). Adv Drug Deliv Rev. 2001; 48: 139-57.

17. Korsmeyer RW, Gurny R, Doelker E, Buri P, Peppas NA. Mechanism of solute release from porous hydrophilic polymers. Int J Pharm. 1983; 15: 25-35.

18. Bakre LG, Ladele BA. Development and evaluation of gastroretentive floating tablets of Ciprofloxacin using Chrysophyllum albidum gum. J Pharm Practice Res. 2019; 49: 240-245.

19. Kaleemullah M, Jiyauddin K, Thiban E, Rasha S, Al-Dhalli S, Budiasih S, Gamal O.E, Fadli A, Eddy Y. Development and evaluation of Ketoprofen sustained release matrix tablet using Hibiscus rosa-sinensis leaves mucilage. Saudi Pharm J. 2017; 25:770-779.

20. Adedokun MO, Ayorinde JO, Odeniyi MA. Compressional, mechanical and release properties of a novel gum in paracetamol tablet formulations. Curr Iss Pharm Med Sci. 2014; 27:187-194.

21. Bamiro OA, Owoduni AS, Bakre LG, Uwaezuoke OJ. Evaluation of Terminalia randii Baker $F$. gum as a disintegrant in paracetamol tablet formulation. J Chem Pharm Res. 2014; 6:155-159.

22. Olobayo O. Kunle (November 29th 2019). Starch Source and Its Impact on Pharmaceutical Applications, Chemical Properties of Starch, Martins Emeje, IntechOpen, DOI: 10.5772/intechopen.89811. Available from: https://www.intechopen.com/books/chemical-properties-of-starch/ starch-source-and-its-impact-on-pharmaceutical-applications

23. Adeleye OA, Femi-Oyewo MN, Odeniyi MA, Ajala TO. Evaluation of Cissus populnea gum as a directly compressible matrix system for tramadol hydrochloride extended-release tablet. J Applied Pharm Sci. 2019; 9(2): 105-111.

24. Lubrizol advanced materials, inc. Formulating controlled release tablets and capsules with carbopol polymers. Pharm Bull. 2011; 31:1-22 